\title{
GAMBARAN PERILAKU HIDUP BERSIH DAN SEHAT (PHBS) SANTRI DI PONDOK PESANTREN AD DIINUL QOYYIM LOMBOK BARAT
}

\author{
Bahjatun Nadrati ${ }^{1}$, Wisnu Probo Wijayanto ${ }^{2}$, Musniati ${ }^{3}$
}

1Program Studi S1 IImu Keperawatan STIKes Yarsi Mataram, NTB. Email: bahjatun.nadrati.bn@gmail.com

2Program Studi IImu Keperawatan STIKes Aisyah Pringsewu, Lampung.

3Fakultas IImu Kesehatan Universitas Nahdlatul Wathan Mataram, NTB. Email: Musniati.suseno@gmail.com

\section{ABSTRACT: CLEAN AND HEALTHY LIVING PROGRAM BEHAVIOR (CHLB) OF STUDENTS AT THE AD DIINUL QAYYIM ISLAMIC BOARDING SCHOOL IN WEST LOMBOK.}

\begin{abstract}
Background: Clean and Healthy Life Behavior (CHLB) the school environment is an effort to empower students, teachers, and the school community to know, want and be able treat CHLB. Health problems faced by student are not different from the problems faced by public school children, even for boarding students who will increase again with environmental health problems in the cottage they occupy.

Purpose: This study was to determine the description of clean and healthy behavior (CHLB) of students at the Ad Diinul Qayyim Islamic Boarding School in West Lombok.

Methods: A descriptive analytical study where the study was conducted with a one-time measurement which aims to find out the description of students' CHLB at the Ad Diinul Qayyim Islamic Boarding School.

Results: The results obtained from the total respondents were 271 students that the majority of respondents were $182(67.9 \%)$ had a picture of clean and healthy behaviors, namely enough, $87(32.1 \%)$ respondents had a picture of clean and healthy life behavior that is good and $2(0.7 \%)$ respondents have a picture of clean and healthy behavior, namely less.

Conclusion; Islamic Boarding School is a form of religious education institution that grows and develops from and for the people who play an important role in the development of human resources, it is expected that the student and leaders and managers of Islamic boarding schools are not only proficient in moral and spiritual development with intellectual nuances religious, but can also be a driver of motivators and innovators in health development, as well as being a role model in clean and healthy lifestyle for the surrounding community.
\end{abstract}

\section{Keywords: Clean and Healthy Life Behavior (CHLB), students, Islamic Boarding School}

Pendahuluan: Perilaku Hidup Bersih dan Sehat (PHBS) tatanan lingkungan sekolah adalah upaya untuk memberdayakan siswa, guru, dan masyarakat lingkungan sekolah agar tahu, mau, dan mampu memperilakukan PHBS. Permasalahan kesehatan yang dihadapi santri-santri tidak berbeda dengan permasalahan yang dihadapi anak sekolah umum bahkan bagi santri yang mondok akan bertambah lagi dengan masalah kesehatan lingkungan yang ada di pondok yang mereka tempati.

Tujuan: Tujuan dari penelitian ini adalah untuk mengetahui Gambaran Perilaku Hidup Bersih dan Sehat (PHBS) Santri di Pondok Pesantren Ad Diinul Qayyim Lombok Barat.

Metode: Penelitian ini merupakan penelitian deskriptif Analitik dimana penelitian dilakukan dengan pengukuran sekali waktu yang bertujuan untuk mengetahui gambaran PHBS santri di Pondok Pesantren Ad Diinul Qayyim.

Hasil: Hasil yang didapatkan dari total responden sebanyak 271 siswa bahwa sebagian besar responden yaitu $182(67,9 \%)$ memiliki gambaran perilaku hidup bersih dan sehat yaitu cukup, $87(32,1 \%)$ responden memiliki gambaran perilaku hidup bersih dan sehat yaitu baik dan $2(0,7 \%)$ responden memiliki gambaran perilaku hidup bersih dan sehat yaitu kurang.

Simpulan; Pondok Pesantren merupakan salah satu bentuk lembaga pendidikan keagamaan yang tumbuh dan berkembang dari oleh dan untuk masyarakat yang berperan penting dalam pengembangan sumber daya manusia, diharapkan para santri dan para pemimpin serta pengelola pondok pesantren tidak saja mahir dalam aspek pembangunan moral dan spiritual dengan intelektual yang bernuansa agamis, namun dapat pula menjadi penggerak motivator dan inovator dalam pembangunan kesehatan, serta menjadi teladan dalam berperilaku hidup bersih dan sehat bagi masyarakat sekitar.

Kata kunci: Perilaku Hidup Bersih dan Sehat (PHBS), santri, pondok pesantren 
GAMBARAN PERILAKU HIDUP BERSIH DAN SEHAT (PHBS) SANTRI

DI PONDOK PESANTREN AD DIINUL QOYYIM LOMBOK BARAT

\section{PENDAHULUAN}

Pembangunan kesehatan pada hakekatnya adalah upaya yang dilaksanakan oleh semua komponen Bangsa Indonesia yang bertujuan untuk meningkatkan kesadaran, kemauan, dan kemampuan hidup sehat bagi setiap orang agar terwujud derajat kesehatan masyarakat yang setinggi-tingginya, sebagai investasi bagi pembangunan sumber daya manusia yang produktif secara sosial dan ekonomis. Keberhasilan pembangunan kesehatan sangat ditentukan oleh kesinambungan antar upaya program dan sektor, serta kesinambungan dengan upaya-upaya yang telah dilaksanakan oleh periode sebelumnya (Kementrian Kesehatan Republik Indonesia, 2015).

Gambaran masyarakat Indonesia di masa depan yang ingin dicapai melalui pembangunan kesehatan adalah masyarakat, bangsa, dan negara yang ditandai oleh lingkungan sehat, perilaku hidup sehat penduduknya, memiliki kemampuan untuk menjangkau pelayanan kesehatan yang bermutu secara adil dan merata, serta memiliki derajat kesehatan yang setinggitingginya di seluruh wilayah Republik Indonesia. Pembangunan semua sektor harus memperhatikan dampaknya terhadap kesehatan, paling tidak harus memberikan kontribusi positifbagi pengembangan perilaku dan lingkungan sehat. Pembangunan kesehatan akan menekankan upaya promotif dan preventif dengan tidak mengesampingkan upayakuratif dan rehabilitatif (Soomro, Zamir, \& Shah, 2012; Handayani, 2012).

Derajat kesehatan masyarakat dipengaruhi oleh 4 (empat) faktor utama yakni lingkungan, perilaku, keturunan dan pelayanan kesehatan (Effendy, 1998; Maulana, 2009). Indikator utama derajat kesehatan masyarakat dapat dilihat antara lain dari angka kematian, angka kesakitan dan status gizi. Pada bagian ini, derajat kesehatan di Provinsi Nusa Tenggara Barat digambarkan melalui Angka Harapan Hidup (AHH), Angka Kematian Bayi (AKB), Angka kematian Ibu (AKI), angka morbiditas beberapa penyakit dan status gizi (Dinas Kesehatan Nusa Tenggara Barat, 2015).

Pondok Pesantren merupakan salah satu bentuk lembaga pendidikan keagamaan yang tumbuh dan berkembang dari oleh dan untuk masyarakat yang berperan penting dalam pengembangan sumber daya manusia, diharapkan para santri dan para pemimpin serta pengelola pondok pesantren, tidak saja mahir dalam aspek pembangunan moral dan spiritual dengan intelektual yang bernuansa agamis, namun dapat pula menjadi motor penggerak, motivator dan inovator dalam pembangunan kesehatan, serta menjadi teladan dalam berperilaku hidup bersih dan sehat bagi masyarakat sekitar (Kementrian Agama Republik Indonesia, 2012).

Pada umumnya kondisi kesehatan di lingkungan pondok pesantren masihmemerlukan perhatian dari pelbagai pihak, baik dalam aspek pelayanan kesehatan,perilaku sehat maupun aspek kesehatan lingkungannya. Berikut beberapa poin permasalahan kesehatan secara umum di pondok pesantren. (1) Berkaitan dengan kesehatan lingkungan: (a) sampah yang berserakan di lingkungan pesantren (b) lantaiasrama jarang dipel (c) bak mandi jarang dikuras dan (e) kasur tidak dijemur.(2) Bekaitan dengan masalah tingkah laku: (a) piring tidak segera dicuci sebelum dansesudah makan (b) sisa makanan yang berserakan di asrama (c) pakaian yang sudahdigunakan bergantungan di dalam asrama (d) santri tidur di lantai, tanpa selimut danalas tidur (e) ember sabun, sepatu dan sandal diletakkan sembarangan di dalamasrama (f) bantal sering dipakai bersama-sama dan $(\mathrm{g})$ sesudah Buang Air Besar(BAB) tidak cuci tangan dengan sabun. (3) Berkaitan dengan masalah gizi: (a) mieinstan dijadikan makanan pokok (b) menu makanan kurang bervariasi (c) santri tidaksarapan pagi (d) mengambil porsi makanan yang tidak sesuai, dan (4) Berkaitandengan masalah sarana dan prasarana: (a) ruang asrama tidak sesuai dengan jumlah penghuni dan (b) kurangnya tempat menjemur pakaian (Afiyah, 2017).

Perilaku Hidup Bersih dan Sehat (PHBS) dilatarbelakangi oleh penetapan visi Indonesia Sehat 2010 dalam Sistem Kesehatan Nasional (SKN) dengan Keputusan Menteri Kesehatan No.131/Menkes/SK/II/2004. Perilaku Hidup Bersih dan Sehat terdiri dari beberapa tatanan yaitu, tatanan rumah tangga, tatanan tempat kerja, tatanan tempat umum, tatanan fasilitas kesehatan dan tatanan lingkungan sekolah (Efendi, \& Makhfudli, 2010; Rorimpandey, Rattu, \& Tumuraang, 2015; Lina, 2017).

Secara nasional, penduduk yang telah memenuhi kriteria PHBS baik tahun 2005 sebesar $27 \%$ meningkat menjadi $36,3 \%$ di tahun 2007

Bahjatun Nadrati' Program Studi Sı llmu Keperawatan STIKes Yarsi Mataram, NTB. Email: bahjatun.nadrati.bn@gmail.com Wisnu Probo Wijayanto ${ }^{2}$ Program Studi llmu Keperawatan STIKes Aisyah Pringsewu, Lampung.

Musniati ${ }^{3}$ Fakultas llmu Kesehatan Universitas Nahdlatul Wathan Mataram, NTB. Email: Musniati.suseno@gmail.com 
kemudian meningkat lagi menjadi sebesar $38,7 \%$ di tahun 2013 dan $40 \%$ di tahun 2015. Sementara itu target nasional tahun 2019 diharapkan penduduk Indonesia yang memenuhi kriteria PHBS baik dapat mencapai angka 80\% (Dinas Kesehatan Nusa Tenggara Barat, 2016; Dinas Kesehatan Lombok Barat, 2012).

Pondok Pesantren Ad Diinul Qayyim merupakan salah satu pondok pesantren terbesar di Nusa Tenggara Barat yang belum menerapkan program poskestren untuk meningkatkan derajat kesehatan warga pesantren. Selama ini pembinaan kesehatan baik secara Promotif, Preventif, Kuratif dan Rehabilitatif hanya dilakukan oleh pihak Puskesmas setempat dengan kurun waktu 3 bulan sekali. Sehingga pemberdayaan kesehatan dilingkungan Pondok Pesantren belum terlaksana secara menyeluruh.

Berhubungan dengan berbagai penyakit yang paling sering diderita oleh warga pondok pesantren, melalui wawancara yang dilakukan diperoleh data, yaitu: scabies, diare, sesak nafas, batuk pilek dan penyakit lainya seperti gangguan pencernaan.

Penelitian sebelumnya yang berhubungan dengan program upaya kesehatan di lingkungan pendidikan atau sekolah adalah penelitian Utama, \& Nasution. (2011) yang menunjukkan adanya pengaruh pembinaan lingkungan sekolah sehat dan ketenagaan dengan pelaksanaan program Usaha Kesehatan Sekolah.

Berdasarkan uraian-uraian diatas, maka penulis tertarik untuk mengetahui Gambaran Perilaku Hidup Bersih dan Sehat (PHBS) Santri di Pondok Pesantren Ad Diinul Qayyim Lombok Barat.

\section{METODE PENELITIAN}

Desain dalam penelitian ini yaitu menggunakan desain deskriptive analitik dimana penelitian dilakukan dengan pengukuran sekali waktu yang bertujuan untuk mengetahui gambaran PHBS santri di Pondok Pesantren Ad Diinul Qayyim 2017.

\section{HASIL}

Tabel 1. Distribusi Frekuensi Responden Berdasarkan Jenis Kelamin $(\mathrm{N}=271)$

\begin{tabular}{lcc}
\hline Jenis Kelamin & Frekuensi & $\mathbf{( \% )}$ \\
& & \\
\hline Laki-laki & 145 & $53,5 \%$ \\
Perempuan & 126 & $46,5 \%$ \\
Jumlah & $\mathbf{2 7 1}$ & $\mathbf{1 0 0 . \%}$ \\
\hline
\end{tabular}

Dari tabel 1 di atas, dapat dilihat bahwa sebagian besar responden yang ada di Pondok Pesantren Ad Diinul Qayyim a berjenis kelamin laki-laki yaitu sebanyak 146 orang $(53,5 \%)$.

Tabel 2. Distribusi Frekuensi Responden Berdasarkan Tingkat Pendidikan ( $N=271)$

\begin{tabular}{lcc}
\hline Pendidikan & Frekuensi & (\%) \\
\hline MA & 219 & $80,8 \%$ \\
MTS & 52 & $19,2 \%$ \\
\hline
\end{tabular}

Dari tabel 2. di atas, didapatkan bahwa sebagian besar responden masih duduk di bangku MA (80,8\%).

\footnotetext{
Bahjatun Nadrati' Program Studi Sı llmu Keperawatan STIKes Yarsi Mataram, NTB. Email: bahjatun.nadrati.bn@gmail.com Wisnu Probo Wijayanto ${ }^{2}$ Program Studi llmu Keperawatan STIKes Aisyah Pringsewu, Lampung.

Musniati ${ }^{3}$ Fakultas llmu Kesehatan Universitas Nahdlatul Wathan Mataram, NTB. Email: Musniati.suseno@gmail.com
} 
GAMBARAN PERILAKU HIDUP BERSIH DAN SEHAT (PHBS) SANTRI

DI PONDOK PESANTREN AD DIINUL QOYYIM LOMBOK BARAT

Tabel 4. Distribusi Frekuensi Pekerjaan Orang tua Responden ( $\mathrm{N}=271$ )

\begin{tabular}{lcc}
\hline Pekerjaan & Frekuensi & $\mathbf{( \% )}$ \\
\hline PNS & 12 & $4,4 \%$ \\
TNI / POLRI & 0 & $0 \%$ \\
Swasta & 197 & $72,7 \%$ \\
Petani / Nelayan & 62 & $22,9 \%$ \\
Jumlah & $\mathbf{2 7 1}$ & $\mathbf{1 0 0 . \%}$ \\
\hline
\end{tabular}

Dari tabel 4. di atas, didapatkan bahwa sebagian besar orang tua responden memiliki jenis pekerjaan sebagai lain-lain (Petani, Buruh, DII), yaitu dengan jumlah 14 orang (26.41\%).

Tabel 5. Distribusi Frekuensi Responden Berdasarkan Umur ( $N=271)$

\begin{tabular}{ccc}
\hline Kelompok Umur & Frekuensi & (\%) \\
\hline $10-15$ & 56 & $20,7 \%$ \\
$16-20$ & 215 & $79,3 \%$ \\
\hline
\end{tabular}

Dari tabel 5. di atas, didapatkan bahwa sebagian besar responden berada pada kelompok usia 16-20 tahun yakni, 215 orang $(79,3 \%)$.

\section{Hasil Analisis}

Tabel 6. Analisis Gambaran PHBS Santri di Pondok Pesantren ( $N=271)$

\begin{tabular}{lcc}
\hline PHBS & Frekuensi & $\mathbf{( \% )}$ \\
\hline Baik & 87 & $32,1 \%$ \\
Cukup & 182 & $67,2 \%$ \\
Kurang & 2 & $0,7 \%$ \\
Jumlah & $\mathbf{2 7 1}$ & $\mathbf{1 0 0 . \%}$ \\
\hline
\end{tabular}

Dari tebel di atas dapat dilihat bahwa sebagian besar responden yaitu $182 \quad(67,9 \%)$ memiliki gambaran perilaku hidup bersih dan sehat yaitu cukup.

Pondok Pesantren merupakan salah satu bentuk lembaga pendidikan keagamaan yang tumbuh dan berkembang dari oleh dan untuk masyarakat yang berperan penting dalam pengembangan sumber daya manusia, diharapkan para santri dan para pemimpin serta pengelola pondok pesantren tidak saja mahir dalam aspek pembangunan moral dan spiritual dengan intelektual yang bernuansa agamis, namun dapat pula menjadi penggerak motivator dan inovator dalam pembangunan kesehatan, serta menjadi teladan dalam berperilaku hidup bersih dan sehat bagi masyarakat sekitar (Peraturan Menteri Kesehatan Republik Indonesia, 2013; Usman, 2013; Jamaluddin, 2012).

Perilaku kesehatan merupakan respon seseorang terhadap stimulus berkaitan dengan sakit dan penyakit, sistem pelayanan kesehatan, makanan minuman serta lingkungan (Notoatmodjo, 2007; Ikhwanudin, 2013; Adliyani, 2015). Perilaku kesehatan terbagi menjadi tiga pola utama, perilaku hidup sehat, perilaku sakit dan perilaku peran sakit contohnya olah raga teratur, makan menu seimbang, istirahat cukup, pengendalian stress, usaha serta cara merespon terhadap sakit, dan penyakit, presepsi terhadap sakit, pengetahuan penyebab gejala penyakit dan lain lain. Selain itu perawatan juga menjaga kesehatan, 
GAMBARAN PERILAKU HIDUP BERSIH DAN SEHAT (PHBS) SANTRI

DI PONDOK PESANTREN AD DIINUL QOYYIM LOMBOK BARAT

pendidikan kesehatan, pertolongan dan tindakan ketika terkena penyakit, serta upaya peningkatan kesehatan lingkungan baik secara individu dan sosial (Heimberg, \& Becker, 2002; Notoatmodjo, 2007).

\section{SIMPULAN DAN REKOMENDASI}

Sebagian besar responden yaitu $182(67,9 \%)$ memiliki gambaran perilaku hidup bersih dan sehat yaitu cukup.Penyampaian informasi oleh tenaga kesehatan secara bertahap sangat perlu dilakukan untuk meningkatkan pengetahuan para santri mengenai PHBS.Pelibatan para ustad dan ustazah dibutuhkan dalam upaya meningkatkan kesadaran para santri akan pentingnya perilaku hidup bersih dan sehat.Perlu perencanaan yang terarah dan berkesinambungan dalam meningkatkan kualitas untuk penerapan.Pendampingan berkelanjutan terhadap masyarakat di Pondok Pesantren Ad Diinul Qayyim penting dilakukan sehingga informasi yang disampaikan sesuai dengan standar yang telah ditetapkan. Rekomendasi: Penelitian lainnya perlu dilakukan dipondok pesantren lainnya sebagai pembanding dan saling melengkapi penelitian lainnya.

\section{DAFTAR PUSTAKA}

Adliyani, Z. O. N. (2015). Pengaruh perilaku individu terhadap hidup sehat. Jurnal Majority, 4(7), 109-114.

Afiyah, A. (2017). Sistem Pendidikan Tauhid di Pondok Pesantren Darul Muttaqin, Desa Bukateja, Kecamatan Balapulang, Kabupaten Tegal Tahun Ajaran 2016/2017 (Doctoral dissertation, Fakultas Tarbiyah dan IImu Keguruan).

Dinas Kesehatan Kabupaten Lombok Barat (2012). Profil Kesehatan Kabupaten Lombok Barat Tahun 2012. Lombok Barat: Dinas Kesehatan Kabupaten Lombok Barat.

Dinas Kesehatan Nusa Tenggara Barat. (2015). Profil Kesehatan Provinsi NTB Tahun 2015. Mataram: Dinkes Prov Mataram

Dinas Kesehatan Nusa Tenggara Barat. (2016). Profil Kesehatan Provinsi NTB Tahun 2016. Mataram: Dinkes Prov Mataram.
Efendi, F., \& Makhfudli, M. (2010). Keperawatan kesehatan komunitas.

Effendy, N. (1998). Dasar-dasar keperawatan kesehatan masyarakat. EGC.

Handayani, D. (2012). Hubungan Dukungan Keluarga dengan kepatuhan lansia dalam mengikuti Posyandu lansia di Posyandu lansia Jetis Desa Krajan Kecamatan Weru Kabupaten Sukoharjo. Gaster: Jurnal Kesehatan, 9(1), 4958

Heimberg, R. G., \& Becker, R. E. (2002). Cognitive-behavioral group therapy for social phobia: Basic mechanisms and clinical strategies. Guilford Press.

Ikhwanudin, A. (2013). Perilaku Kesehatan Santri:(Studi Deskriptif Perilaku Pemeliharaan Kesehatan, Pencarian dan Penggunaan Sistem Kesehatan Dan Perilaku Kesehatan Lingkungan Di Pondok Pesantren Assalafi Al Fithrah, Surabaya). Jurnal Sosial dan Politik, 2(2), 3.

Jamaluddin, M. (2012). Metamorfosis Pesantren Di Era Globalisasi. KARSA: Journal of Social and Islamic Culture, 20(1), 127-139.

Kementrian Agama Republik Indonesia. (2013). Perilaku komunitas Muslim perkotaan dalam mengonsumsi produk halal.

Kementrian Kesehatan Republik Indonesia. (2015). Profil Kesehatan Indonesia 2014. Jakarta: Kementrian Kesehatan RI.

Lina, H. P. (2017). Perilaku Hidup Bersih dan Sehat (PHBS) Siswa di SDN 42 Korong Gadang Kecamatan Kuranji Padang. Jurnal Promkes, 4(1), 92-103.

Maulana, H, D. (2009). Promosi kesehatan. EGC.

Notoatmodjo, S. (2007). Kesehatan masyarakat. Jakarta: Rineka Cipta.

Permenkes, R. I. (2013). Nomor 71 Tentang Pelayanan Kesehatan Pada Jaminan Kesehatan Nasional.

Bahjatun Nadrati' Program Studi S1 llmu Keperawatan STIKes Yarsi Mataram, NTB. Email: bahjatun.nadrati.bn@gmail.com Wisnu Probo Wijayanto ${ }^{2}$ Program Studi llmu Keperawatan STIKes Aisyah Pringsewu, Lampung.

Musniati ${ }^{3}$ Fakultas llmu Kesehatan Universitas Nahdlatul Wathan Mataram, NTB. Email: Musniati.suseno@gmail.com 
GAMBARAN PERILAKU HIDUP BERSIH DAN SEHAT (PHBS) SANTRI

DI PONDOK PESANTREN AD DIINUL QOYYIM LOMBOK BARAT

Rorimpandey, H. M., Rattu, A. J. M., \& Tumuraang, M. N. (2015). Faktor-Faktor Yang Berhubungan Dengan Perilaku Hidup Bersih Dan Sehat (PHBS) Pada Siswa Di SMP Negeri 2 Tompaso. Tumou Tou, 1(2).

Soomro, K., Zamir, A. R., \& Shah, M. (2012). UCF101: A dataset of 101 human actions classes from videos in the wild. arXiv preprint arXiv:1212.0402.
Usman, M. I. (2013). Pesantren Sebagai Lembaga Pendidikan Islam (Sejarah Lahir, Sistem Pendidikan, Dan Perkembangannya Masa Kini). Jurnal al-Hikmah, 14(1), 127-146.

Utama, S., \& Nasution, K. (2011). Pengaruh Pembinaan Puskesmas Terhadap Pelaksanaan Program Usaha Kesehatan Sekolah Di Sekolah Dasar Kecamatan Medan Amplas Tahun 2011. 